\section{enc. João Paulo Seara \\ Cardoso, \\ Teatro de Marionetas do \\ Porto, 2011 \\ (Sara Henriques), \\ fot. Susana Neves.}

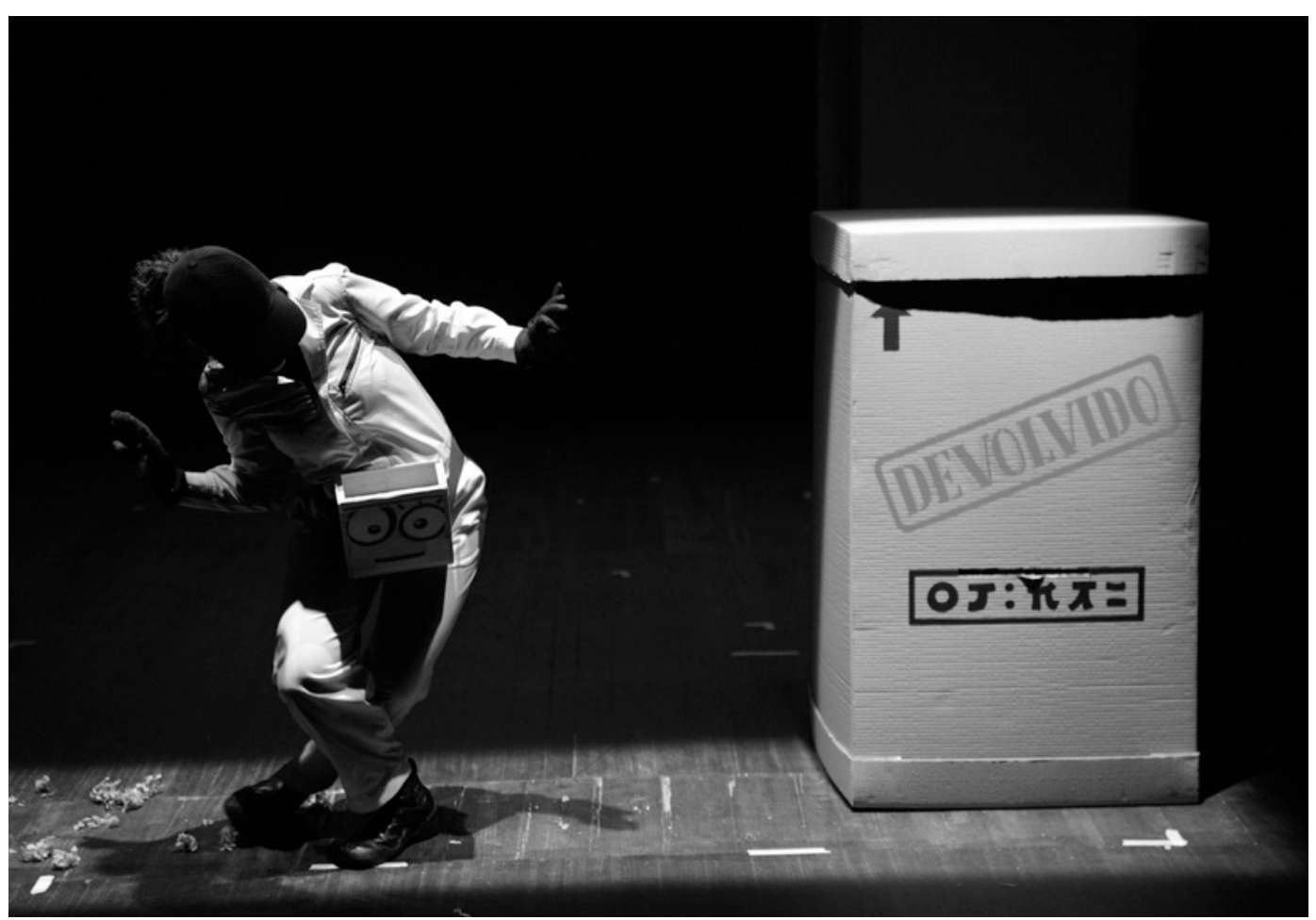

\title{
Da fragilidade dos objectos e dos seres segundo João Paulo Seara Cardoso
}

\section{Christine Zurbach}

Título: Frágil. Encenação e cenografia: João Paulo Seara Cardoso e colectivo. Marionetas e objectos cénicos: Rui Pedro Rodrigues. Figurinos: Pedro Ribeiro. Sonoplastia: Miguel Reis. Coordenação de movimento: Isabel Barros. Desenho de luz: Roy Peter. Animação video: Grifu. Produção:Sofia Carvalho. Interpretação: Rui Queirós de Matos, Sara Henriques, Sérgio Rolo. Co-produção: Teatro de Marionetas do Porto Et Artemrede. Fotografia: Susana Neves. Local e data de estreia: Balleteatro Auditório, Porto; 13 de Janeiro de 2011.

Último espectáculo encenado por João Paulo Seara Cardoso (1956-2010) com a companhia do Teatro de Marionetas do Porto que criou em 1988, concluído já depois do seu falecimento pelos actores da companhia, Frágilé apresentado no sítio da companhia como uma peça para crianças, no sentido pleno que JPSC soube dar a tal classificação numa época que promove o teatro de marionetas como espaço por excelência para a imaginação, a criatividade e o prazer lúdico associado ao requinte estético. Na verdade, no trabalho de JPSC, as classificações etárias revelam-se desnecessárias como o prova o acolhimento entusiasta e comovido que mereceu por parte do público da Bienal Internacional de Marionetas de Évora de 2011. Sendo um espectáculo concebido nos moldes contemporâneos do teatro de marionetas, surpreende pela versatilidade dos meios e das linguagens de que é

Consultar a apresentação do perfil do Teatro de Marionetas do

Porto no composto: no centro reina a marioneta/objecto material, com a aparência do objecto tradicional desta forma de teatro como todos a conhecemos: uma figura manipulada lquase antropomórfica se não fosse a sua cabeça em formato quadrado de caixote de papelão com dois olhos pintados), com um corpo, braços e pernas. Para Ihe dar vida, o espectáculo recorre a um espaço abstracto, concebido como uma área para o jogo teatral, sem preocupação realista ou sequer simbólica, e a três actores que com ele contracenam numa relação em que manipulado e manipulador se confundem para o nosso (e seu) grande prazer.

Para o público que JPSC soube fidelizar, é nesse confronto com os actores que a manipulam (o que a distingue da marioneta tradicional ou clássica) que a marioneta, tal como a concebeu na sua escrita artística e como surge agora em Frágil, representa o modo específico de inscrição do espectáculo na estética e na dramaturgia contemporânea deste tipo de teatro. Entende-se aqui a dramaturgia no uso corrente do termo no teatro, como trabalho hermenêutico, de elaboração do sentido que o espectáculo oferece à inteligência e à sensibilidade do espectador. Nas orientações da companhia de Teatro de Marionetas do Porto domina uma concepção não convencional da marioneta, entendida "no limite (como) objectos cinéticos"1 dando prioridade a um teatro poético e imagético que se relaciona com a dança, as artes visuais, a música e o video, em articulação com um texto cujo peso 

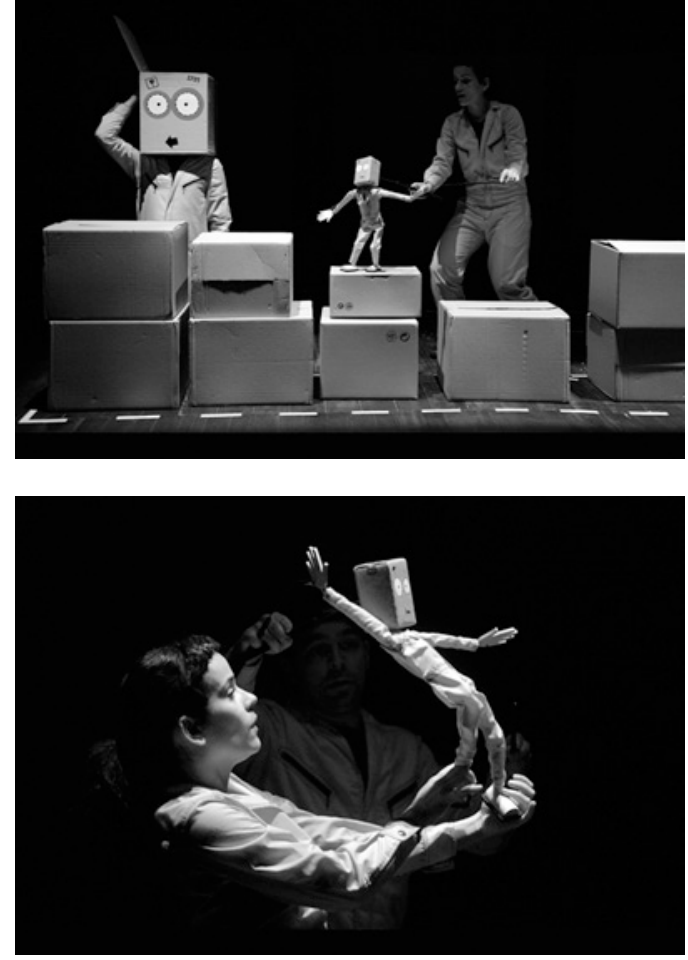

e presença são variáveis, umas vezes escolhido no repertório dos autores clássicos ou contemporâneos mais conceituados, como António José da Silva, Shakespeare ou Beckett, e outras vezes criado com materiais diversos. Aqui, no espectáculo Frágil, o texto é praticamente inexistente, deixando a quase totalidade do espaço sonoro a sons vocais, com palavras nem sempre proferidas com nitidez, que criam, numa prazenteira cumplicidade lúdica, um tecido multifacetado, elaborado com a ajuda dos sons musicais. A banda sonora é composta por um arranjo entre temas musicais que servem as várias sequências do espectáculo, em que a tonalidade dominante é festiva e alegre. Juntos compõem uma paisagem sonora com uma presença constante ao longo do espectáculo, quebrada por breves intervalos de silêncio. Desse modo de lidar com os sons, os ruidos (uma campainha de bicicleta abre a primeira cena, ainda no escuro, juntamente com a luz do farol dessa bicicleta em movimento), resulta uma maior intensidade da pequena narrativa final, evocada suavemente pela actriz, uma história de amor que se desenrolou nas margens de um lago, há muito tempo, enquanto a mesma bicicleta volta a aparecer, mas assumindo agora uma outra narrativa: no início, era um instrumento de trabalho, para transporte de caixas e caixotes, e no final, é o cúmplice para seguir um caminho a dois, numa viagem feliz.

Nesse sentido, promovendo emoções simples e ao mesmo tempo profundas, que levam qualquer um a interrogar o sentido da existência, o espectáculo Frágilé portador dos valores éticos, filosóficos e estéticos que sustentam toda a belissima obra que JPSC nos deixou. Criador ímpar no panorama da marioneta contemporânea em Portugal e de projecção internacional, aprendeu com o Teatro Dom Roberto da barraca de feira como se podia manter viva uma tradição portuguesa que resistia ao desaparecimento, e soube confrontar-se com o desafio lançado ao teatro de marionetas por outros artistas em prol da sua renovação nos anos 1970-80. ${ }^{2}$

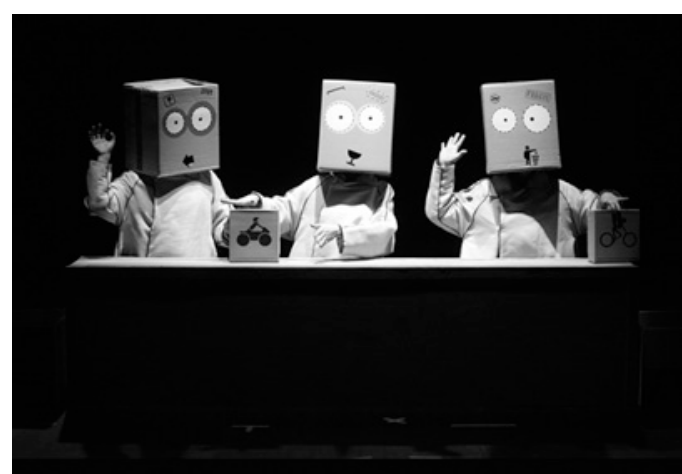

Fê-lo nos locais certos como o era e continua hoje a ser o Instituto Internacional do Teatro de Marionetas de Charleville-Mézières, e no momento certo: despida do seu estatuto de parente pobre e por vezes envergonhado, a marioneta tinha finalmente acesso ao mundo do teatro, ele próprio atravessado por uma imparável revolução artística. Abraçou-a com a serenidade de quem sabia que já era uma referência para as vanguardas desde o início do século e para os nomes maiores entre os artistas da nossa contemporaneidade como Kantor.

A criação de Frágil foi antecedida por longos anos de um trabalho artístico concebido como um percurso de pesquisa constante em torno das potencialidades inesgotáveis da marioneta em que as encenações se sucederam, algumas recorrendo a textos do repertório, outras com recursos tecnológicos por vezes sofisticados. Para compor Frágil, o encenador recorreu em três momentos do espectáculo a animações com vídeo que, pelo seu carácter virtual, aproximam o espectador de algo sonhado ou apenas imaginado, completando a narrativa das viagens empreendidas pelas marionetas e pelas pessoas, entre saltos e corridas num tapete rolante, uma via de cintura ladeada por candeeiros e casas e uma paisagem à beira mar, com uma casa de férias. As imagens evocam emoções simples que para todos podem também ser recordações de algo já vivido, da busca ou da procura de alguém ou de um lugar. Mas nessa caminhada criativa, a marioneta e o actor estiveram juntos, num confronto em torno de uma pergunta que também poderá ser uma dúvida sem resposta que nos lançam os seres ditos inanimados, objectos ou matérias, a nós, seres ditos vivos: qual será a vraie vie, entre aquela que designamos por "realidade" e aquela que criamos com a nossa imaginação? Como responder ao certo?

Depois da cena inicial que nos dá a conhecer três operários de um armazém, vestidos com um fato-macaco amarelo, que tentam resolver o problema do transporte de encomendas metidas em caixotes etiquetados "Frágil" que deveriam ser empilhados numa bicicleta endiabrada, mas que não param de cair, da última e única caixa chegada ao destino, misteriosamente sairá um som (reclamação ou chamada de socorro?). Aberto o caixote com muita cautela, descobre-se uma marioneta, vestida como os operários como uma réplica em ponto pequeno do mundo dos seres vivos, e com uma caixa no lugar da cabeça, que vai arrastá-los para um divertido jogo com pulos no ar, de caixote em caixote, acabando num banho de esferovite antes de ser repentinamente reintegrada no mundo dos objectos e fechada no caixote que, como para ela, numa duplicação de imagens, passou a ser a cabeça
$<>$ Frágil, enc. João Paulo Seara Cardoso, Teatro de Marionetas do Porto, 2011 (< Sérgio Rolo e Sara Henriques; > Sérgio Rolo, Sara Henriques e Rui Queirós de Matos; v Sara Henriques), fot. Susana Neves.

João Paulo Seara Cardoso, "As Marionetas estão na vanguarda das Artes Cénicas", entrevista por Valdemar Cruz, in Catálogo da exposição, Museu da Marioneta de Lisboa, 2001. Consultar site www.marionetasdo porto.pt 


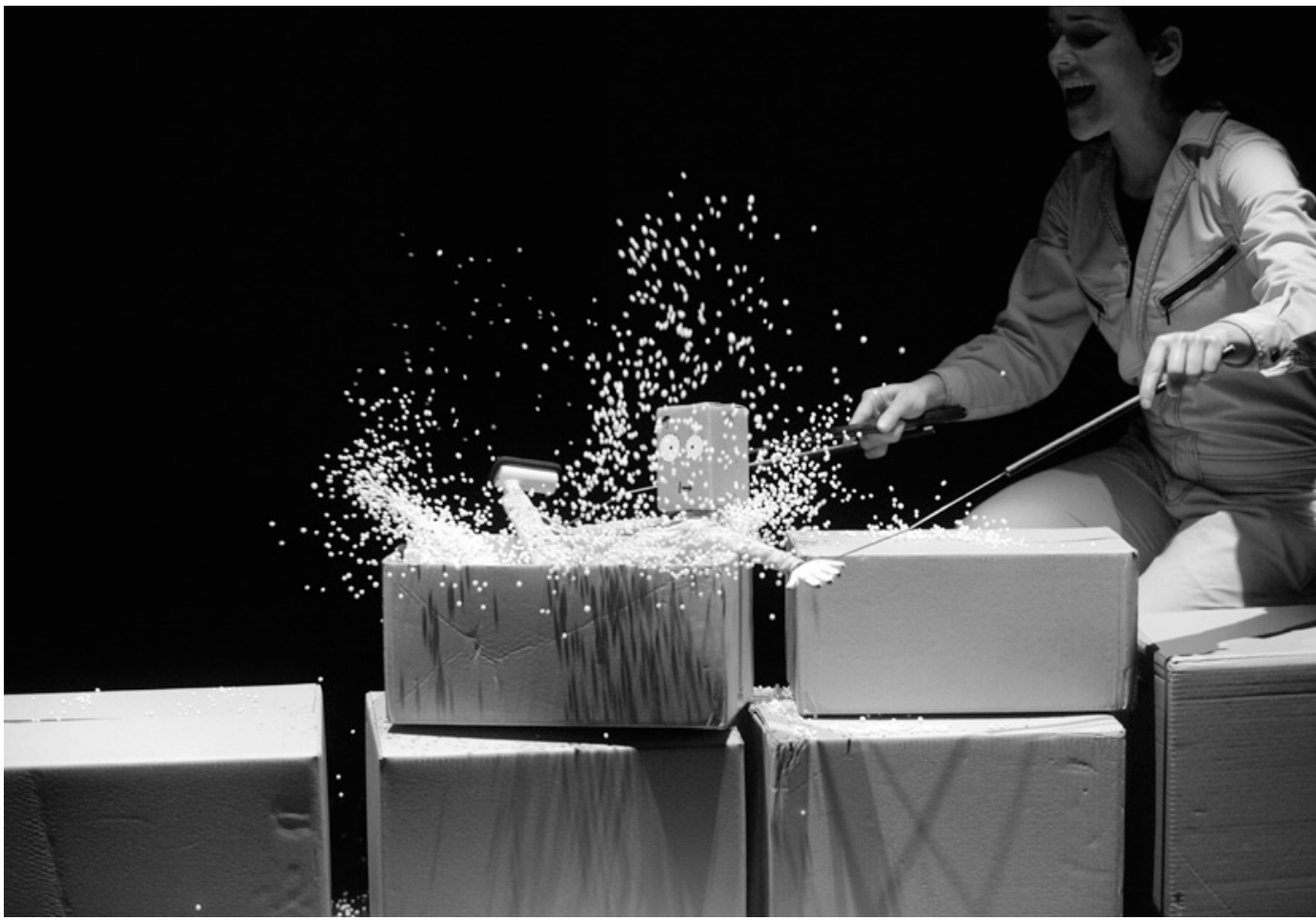

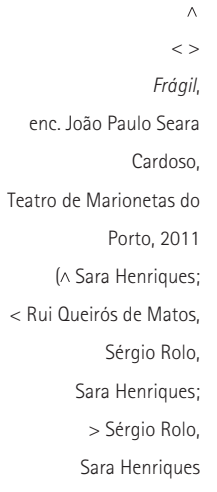

e Rui Queirós de Matos),

fot. Susana Neves.

3 texto é reproduzido a partir do site www.marionetasdo

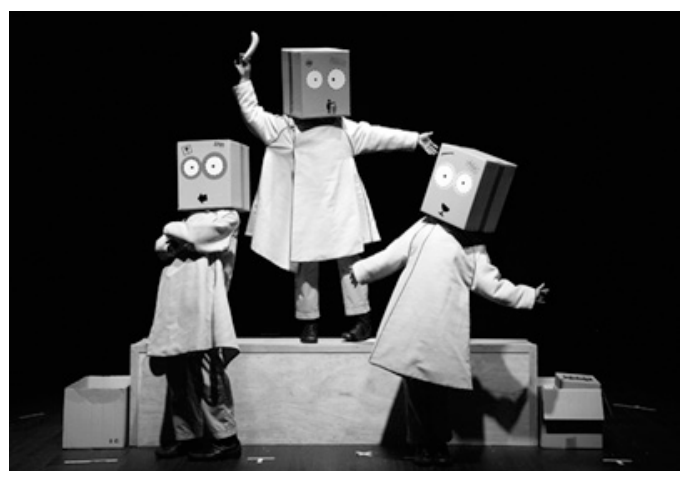

de um dos marionetistas. Se nesse quadro é o objecto que estimula o jogo dos actores-marionetistas, invertendo a relação convencional entre seres vivos e objectos inanimados, no momento seguinte são os corpos dos actores que surgem como marionetas de um teatro de sombras por trás dos três biombos que delimitam espaços diversos ao longo do espectáculo de acordo com as cenas. Dois espanadores coloridos surgem

inesperadamente, num simulacro de teatro de fantoches por cima do biombo, e noutra sequência, os braços e as pernas da actriz são manipulados como se ela fosse um objecto, do mesmo modo que toda uma curta cena evoca a linguagem gestual em que o corpo se torna capaz de escrever palavras.

É sobre um assunto tão antigo quanto o é a arte do teatro (não é disto que Aristóteles nos fala?), deste modo de fazer de conta sem mentir, que o espectáculo Frágil de JPSC interpela o espectador, por intermédio das imagens da vida que enquanto seres vivos emprestamos/damos às marionetas. Tirando-o do seu sossego de modo humorístico e enternecido, o encenador de Frágil propõe simplesmente ao espectador que um caixote de papelão que não passa de matéria inerte, útil para resolver questões práticas do nosso quotidiano, possa ser mais do que um

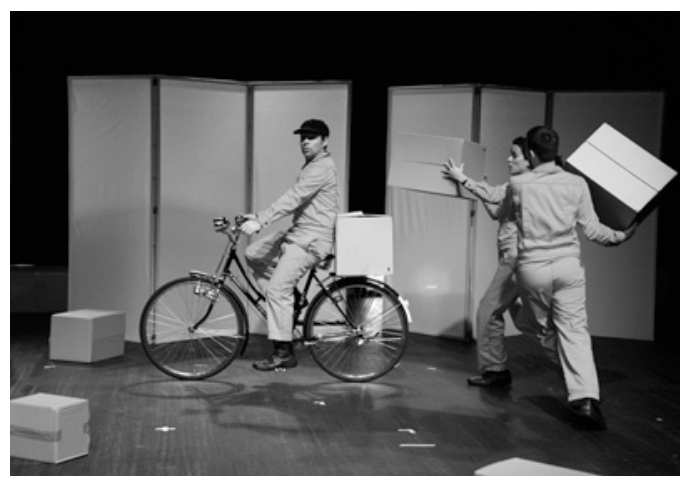

objecto manipulado e sugere também que um actor atarefado, a braços com a agitação própria do seu trabalho em cena, seja algo mais do que uma pessoa habilitada (e habilidosa) que move objectos e que se mova, também ele, dentro da lógica do mundo e da linguagem dos objectos.

E é à marioneta que compete o papel privilegiado de discursar lúdica e artisticamente sobre tudo isto, arrastando com ela os actores. No texto de apresentação do espectáculo, somos avisados de que "Uma coisa às vezes não é aquilo que ela é. Às vezes as coisas gostam de ser outras coisas, por exemplo de serem como as pessoas. Gostam de se mexer, de rir, de gostar e de não gostar." E como estamos no teatro, lugar onde ainda se podem contar histórias, Frágil confirma que "As pessoas/coisas e as coisas/pessoas servem para contar histórias (seguindo as) regras da imaginação!"3. Fiel ao seu projecto, o artista João Paulo Seara Cardoso não nos podia deixar uma mensagem mais coerente: os seres e os objectos são semelhantes. Na sua fragilidade, que os torna pereciveis, mas também na sua capacidade imensamente criativa de refazerem juntos o mundo em que juntos habitamos. 